\title{
CLINICOPATHOLOGICAL PROFILE OF CERVICAL CANCER PATIENTS ATTENDING IN A SPECIALIZED HOSPITAL
}

\author{
AFROJ $\mathrm{S}^{1}$, BANU MA ${ }^{2}$, SULTANA $\mathrm{S}^{3}$, JAHAN R ${ }^{4}$, RAHMAN $\mathrm{S}^{5}$, BEGUM $\mathrm{N}^{6}$
}

\begin{abstract}
Background: Cervical cancer is one of the leading causes of death among women in our country. .It is a preventable disease and early carcinoma cervix can be cured by proper treatment. Lack of countrywide well accepted screening program of cervical cancer may be a cause of this hidden advancement of disease.
\end{abstract}

Objectives: To assess the clinical and pathological profile of patients with cervical cancer.

Method: This cross sectional descriptive study was conducted in the Department of Gynaeoncology of National Institute of Cancer Research \& Hospital (NICRH) from January, 2011 to December, 2011. Initially 76 patients were enrolled in the study by purposive sampling. Thereafter they were scrutinized by eligibility criteria and ultimately 67 patients were finalized. A case record form was prepared which was pre-structured, interview and observation based and peer reviewed. Data regarding socio-demographic, clinical and pathological profiles were collected in standard data sheet. Data were recorded, compiled, edited and analyzed. P-value was determined as significant at $<0.05$.

Results: The mean age of 67 patients were $44.9 \pm 12.01$ years (age range: $20-75$ years). $74.6 \%$ patients were married, $79.1 \%$ were housewife and $50.7 \%$ were illiterate/only can sign. The household income was $<10,000 \mathrm{BDT} /$ month in case of $58.2 \%$ cases whereas 10,000-25,000 in $38.8 \%$ cases. Among study population $47.8 \%$ and $31.3 \%$ adenoc patients were staged as stageII and stage-III, on the contrary $19.4 \%$ and $1.5 \%$ were staged as stage I and IV. Majority of patients $86.57 \%$ are suffering from aqueous cell carcinoma and only $13.43 \%$ had carcinoma. Most of the patient in advanced stage $32.75 \%$ in stage IIIB, $29.3 \%$ stage IIB. In this study all patients had excessive $P / V$ discharge, among them $67.16 \%$ foul smelling and $19.4 \%$ blood stained, $764.1 \%$ irregular P/V bleeding and $86.56 \%$ postcoital bleeding. Regarding identifiable risk factors grand mutipara $79.1 \%$, low socioeconomic group $58.2 \%$ and early marriage $49.25 \%$,

Conclusion: There are several risk factors available among our cervical cancer patients like early marriage, multipariy, low socioeconomic coditioand, ,multiple sex partner. Most of them are suffering from squamous cell carcinoma. The alarming clinical presentation such as blood stained or foul smelling PV discharge, irregular PV bleeding and postcoital bleeding should be considered seriously for seeking medical attention.

Key words: Cervical Cancer, Risk factors, Clinicopathological profile.

J Dhaka Med Coll. 2017; 26(2) : 117-121

\section{Introduction:}

Globally, $13 \%$ of all deaths are observed due to cancer ${ }^{1}$. Cervical cancer is one of the principal culprits that is responsible for 2, 66,000 deaths annually according to GLOBOCON 2012 reports $^{2}$. It claims $12 \%$ of all women cancers. $85 \%$ of all cervical cancers are found in the third world ${ }^{3}$.In our neibouring country India almost $21-23 \%$ of all female cancers is cervical cancer. Unfortunately, we have no such population

1. Dr. Sultana Afroj, Associate Professor, Department of Obstetrics \& Gynaecology, Dhaka Medical College, Dhaka

2. Dr. Mahbuba Akhter Banu, Associate Professor, Department of Obstetrics \& Gynaecology, Sir Salimullah Medical College, Dhaka

3. Dr. Sufia Sultana, Associate Professor, Department of Obstetrics \& Gynaecology, Dhaka Medical College, Dhaka

4. Dr. Raunak Jahan, Junior Consultant, Department of Obstetrics \& Gynaecology, Shaheed Suhrawardy Medical College, Dhaka

5. Dr. Shamima Rahman, Junior Consultant, Department of Obstetrics \& Gynaecology, Dhaka Medical College, Dhaka

6. Dr. Nazneen Begum, Associate Professor, Department of Obstetrics \& Gynaecology, Dhaka Medical College, Dhaka

Correspondence : Dr. Sultana Afroj, Associate Professor, Department of Obstetrics \& Gynaecology, Dhaka Medical College, Dhaka, Phone: 01714262412,E-mail: safroj31@yahoo.com 
based data regarding this dreadful condition. It is certain that all the important risk factors of this disease like early marriage, early starting of sexual activity, multiparity, socioeconomic condition and higher incidence of sexually transmitted diseases (STDs) are commonly observed among our women ${ }^{5}$. The good result of cervical cancer prevention and screening are yet to be observed in our country which is a driving force of reduction of cervical cancer in the western world 6 . Besides, still the lack of awareness in mass population coupled with financial and geographical inaccessibility to the standard cancer care are the principal barriers in this regard.

National Institute of Cancer Research \& Hospital is the only super specialized dedicated cancer hospital in Bangladesh. It is a 300 bed hospital that has to tackle the massive burden of cancer population of Bangladesh. It was mentioned in Worldometer, 20177\% World Bank, $2017^{8}$ that among $162,910,864$ people $18.5 \%$ of the total population are making $<1.9$ USD per day. For this reason majority country people have to receive care through government sponsored hospitals and health centers. NICRH is also functioning as the hub of zenith cancer care center in the country.

The main aim of this study was to observe the clinical and pathological profiles of cervical cancer patients in NICRH.

\section{Materials \& Methods:}

This cross-sectional observational study was conducted in the department of Gynae-Oncology in National Institute of Cancer Research \& Hospital, Mohakhali, Dhaka from January, 2011 to December, 2011. Initially, 76 patients were enrolled in the study by purposive sampling. Thereafter, the moribund patients and the patients who denied to participate in the study were excluded. So ultimately the total sample size was 67. A pre-structured, interview and observation based, peer-reviewed case record form was prepared. Data were recorded in the standard data sheet. It was then compiled, edited and analyzed in the special software SPSS (Statistical Package for Social Science, Chicago, USA) version 23. Data analysis was done by chi square test. Mean, frequency and percentages of different variables were also determined. P-value was determined significant at $<0.05$.

\section{Results:}

\section{Table-I}

Distribution of patients according to age $(N=67)$

\begin{tabular}{lc}
\hline Age group (in years) & Frequency $(\%)$ \\
\hline $20-30$ & $6(9 \%)$ \\
$31-40$ & $25(37.3 \%)$ \\
$41-50$ & $18(26.9 \%)$ \\
$51-60$ & $14(20.9 \%)$ \\
$61-70$ & $4(6 \%)$ \\
\hline Total & $67(100 \%)$ \\
\hline Mean age \pm SD (in years) & $44.9 \pm 12.01$ \\
Age range (in years) & $20-75$
\end{tabular}

Table- 1 shows that out of 67 patients, 37.3\%, $26.9 \%$ and $20.9 \%$ belonged to age group $31-40$ years, 41-50 years and 51-60 years respectively. $9 \%$ and $6 \%$ patients were two extreme of age like, 20-30 years and 61-70 years age group respectively. The mean age of the participants was $44.9 \pm 12.01$ years (age range: $20-75$ years).

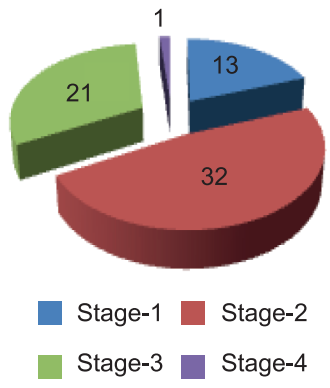

Fig.-1: Distribution of patients according to staging of cervical cancer $(n=67)$.

Fig. -1 shows that $47.8 \%$ and $31.3 \%$ patients were staged as stage-II and III respectively. On the contrary, $19.4 \%$ and $1.5 \%$ were staged as stage-I and IV respectively.

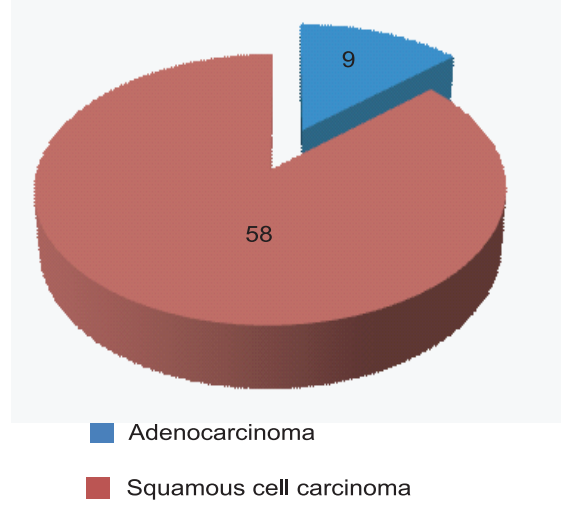

Fig.-2: Distribution of patients according to histopathology report $(N=67)$. 
Figure- 2 reveals that out of 67 patients, $86.57 \%$ and $13.43 \%$ were found as squamous cell carcinoma and adenocarcinoma respectively.

Table-II

Epidemiological characteristics of cervical cancer patients $(N=67)$

\begin{tabular}{lc}
\hline Variables & Values (N=67) \\
\hline Age (mean \pm SD) in years & $44.9 \pm 12.01$ \\
Marital status (n,\%) & \\
$\quad$ Married & $50(74.6 \%)$ \\
$\quad$ Divorced & $2(3 \%)$ \\
Widow & $13(19.4 \%)$ \\
Occupational status (n, \%) & \\
$\quad$ Service & $3(4.5 \%)$ \\
Business & $3(4.5 \%)$ \\
Day labourer & $8(11.9 \%)$ \\
Housewife & $53(79.1 \%)$ \\
Educational status & $34(50.7 \%)$ \\
Illiterate/only can sign & $28(41.8 \%)$ \\
Primary & $4(6 \%)$ \\
SSC & $1(1.5 \%)$ \\
Graduate \& above & $(\mathrm{BDT} / \mathrm{month})$ \\
Household income status (n, \%) \\
$<10,000$ \\
10000 - 25000 & $39(58.2 \%)$ \\
$\quad$ 25000 & $26(38.8 \%)$ \\
Smoking status (n, \%) & $2(3 \%)$ \\
Yes & \\
No & $16(23.9 \%)$ \\
Smokeless tobacco (n, \%) & $51(76.1 \%)$ \\
Yes & \\
No & $39(58.2 \%)$ \\
\hline
\end{tabular}

Table-II shows the overall epidemiological characteristics of the sample population highest values of different variables revealed that $74.6 \%$ patients were married $79.1 \%$ were housewife, $50.7 \%$ were illiterate or only can sign, $58.2 \%$ from low socioeconomic status $(<10,000 /$ month), $76.1 \%$ non-smokers, $58.2 \%$ took smokeless tobacco.

\section{Table-III}

Distribution of patients according to risk factors $(N=67)$

\begin{tabular}{lc}
\hline Risk factors & $\begin{array}{c}\text { Frequency (\%) } \\
(\mathrm{n}=67)\end{array}$ \\
\hline Grand multiparity (>4) & $53(79.1 \%)$ \\
Age of marriage(<20years) & $33(49.25 \%)$ \\
Low socioeconomic group & $39(58.2 \%)$ \\
Multiple sex partner & $15(22.4 \%)$ \\
OCP use & $30(44.8 \%)$ \\
High risk male partner & $12(17.9 \%)$ \\
Poor personal hygiene & $42(62.7 \%)$ \\
Coitus during menstruation & $21(31.4 \%)$ \\
\hline
\end{tabular}

Table-3 reveals that the presence of different risk factors that may be responsible for cervical cancer. It was found here that $79.1 \%$ were grand multiparous, $.49 .25 \%$ were (less than 20 years) early age marriage group, $58.2 \%$ from low socioeconomic group, $22.4 \%$ had multiple sex partner, $44.8 \%$ used OCP, $17.9 \%$ had high risk male partner who were polygamous, $62.7 \%$ adopted poor personal hygiene and $31.4 \%$ practiced coitus during menstruation.

\section{Table-IV}

Staging of cervical cancer in relation to histological variants $(N=67)$

\begin{tabular}{lcccc}
\hline & Total & Squamous cell carcinoma & Adenocarcinoma & P-value \\
\hline IB & $13(19.4 \%)$ & $11(18.96 \%)$ & $2(22.22 \%)$ & $0.7^{\text {NS }}$ \\
IIA & $12(17.91 \%)$ & $9(15.5 \%)$ & $3(33.33 \%)$ & \\
IIB & $20(29.85 \%)$ & $17(29.31 \%)$ & $3(33.33 \%)$ & \\
IIIA & $1(1.49 \%)$ & $1(1.72 \%)$ & $0(0 \%)$ & \\
IIIB & $20(29.85 \%)$ & $19(32.75 \%)$ & $1(11.11 \%)$ & \\
IVA & $1(1.49 \%)$ & $1(1.72 \%)$ & $0(0 \%)$ & \\
\hline Total & 67 & $58(100 \%)$ & $9(100 \%)$ & \\
\hline
\end{tabular}

Table-4 reveals Squamous cell carcinoma $18.96 \%, 44.81 \%, 34.47 \%$ and $1.72 \%$ in stage I, II, III and IV and rest of the patients had adenocarcinoma. 
Table-V

Clinical profile and their correlation to diagnosis $(N=67)$

\begin{tabular}{lccccccc}
\hline Clinical profile & Stage-I & \multicolumn{2}{c}{ Stage-II } & \multicolumn{2}{c}{ Stage-III } & Stage-IV & p-value \\
& IB & IIA & IIB & IIIA & IIIB & IVA & \\
\hline $\begin{array}{l}\text { Discharge status } \\
\text { Foul smelling(n=45) }\end{array}$ & $0(0 \%)$ & $10(22.22 \%)$ & $16(35.55 \%)$ & $1(2.22 \%)$ & $17(37.77 \%)$ & $1(2.22 \%)$ & $0.79^{\mathrm{NS}}$ \\
$\begin{array}{l}\text { Blood stained(n=8) } \\
\text { Irregular PV bleeding }\end{array}$ & $0(0 \%)$ & $2(25 \%)$ & $4(50 \%)$ & $0(0 \%)$ & $2(25 \%)$ & $0(0 \%)$ & \\
Present (n=43) & $2(4.65 \%)$ & $5(11.62 \%)$ & $14(32.55 \%)$ & $1(2.32 \%)$ & $17(39.53 \%)$ & $0(0 \%)$ & $0.001^{\mathrm{S}}$ \\
Absent (n=24) & $11(45.83 \%)$ & $7(29.16 \%)$ & $6(13.95 \%)$ & $0(0 \%)$ & $3(12.50 \%)$ & $1(4.10 \%)$ & \\
Post coital bleeding & & & & & & & \\
Present (n=58) & $11(18.96 \%)$ & $11(18.96 \%)$ & $17(29.31 \%)$ & $1(1.72 \%)$ & $17(29.31 \%)$ & $1(1.72 \%)$ & $0.983^{\mathrm{NS}}$ \\
Absent (n=9) & $2(22.22 \%)$ & $1(11.11 \%)$ & $3(33.33 \%)$ & $0(0 \%)$ & $3(33.33 \%)$ & $0(0 \%)$ & \\
\hline
\end{tabular}

Table- 5 shows that out of 67 patients all had excessive PV discharge. Among them $45(82.08 \%)$ had foul smelling and $8(17.91 \%)$ bloody discharge. All 13 patients of stage IB had though excessive PV discharge but it was neither foul smelling nor blood stained. Irregular PV bleeding was also observed in case of 43 (64.18\%) patients, 58(86.56\%) patients noticed post coital bleeding. There was no statistically significant difference $(p=>0.05)$ found between the stages in relation to clinical presentation except irregular PV bleeding $(\mathrm{p}=0.001)$.

\section{Discussion:}

Cervical cancer is one of the most dreadful conditions in the world of Gynae-oncology. The annual incidence of this disease in Bangladesh is approximately $11956^{9}$. The developing and least developed countries claim a handsome figure of cervical cancer $(80 \%)$ in all female cancer, incidence among the globally affected women $(4,68,000)^{10}$. The percentage of cervical cancer in NICRH Dhaka, Bangladesh comprises $19.2 \%$ of all admitted cancer patient ${ }^{11}$.

The mean age of our sample population was observed as 44.9 \pm 12.01 years (age range: $20-$ 75 years). These results are almost similar to the reports of Jabeen S et al. and her colleagues in 2014 from the same study place ${ }^{12}$.

In this study $74.6 \%$ of our respondents were married whereas $19.4 \%$ and $3 \%$ were widowed or divorced respectively. Naturally, we haven't found any unmarried patient in our reports which was supported by that of Jabeen $\mathrm{S}$ et al. ${ }^{12}$. In that study, $90 \%$ of their patients were married which was subsequently followed by $8 \%$ and $2 \%$ widowed and divorced respondents respectively ${ }^{12}$.

Out of 67 respondents, $58.2 \%, 38.8 \%$ and $3 \%$ belonged to $<10,000,10,000-25,000$ and $>25,000$ BDT per month household income respectively. As low socioeconomic condition is an established risk factor ${ }^{13}$ in case of cervical cancer our study respondents may also be affected by this factor.

The earliest symptom of cervical cancer is thin watery blood tinged discharge that frequently overlooked or unrecognized by patients ${ }^{14}$. We have observed excessive per vaginal discharge as the earliest presenting complaints of all patients, irregular per vaginal bleeding was observed in case of $80.59 \%$ cases. Post coital bleeding was recorded in case of $86.56 \%$ cases.

Cervical cancer is the only clinical condition of Gyneoncology which is staged on the basis of tumor size, vaginal or parametrial involvement, bladder/rectum extension and distant metastases. These require examination under anesthesia, imaging studies like MRI to determine tumor size, degree of stromal penetrations, parametrial involvement, vaginal extension and corpus extension with high $\operatorname{accuracy}^{15}$.

We have also followed the procedures according to ESMO guideline to stage the disease. We have found $47.8 \%, 31.3 \%, 19.4 \%$ and $1.5 \%$ patients were found stage II, stage-III, stage-I and stageIV respectively. Likewise, the prevalence of late stage at initial presentation to the OPD among 
cervical cancer patients are reported. 98\% from Zaria, Nigeria, 90\% from National Hospital, Tanzania, 81\% from Nepal and 80\% from Gujrat cancer and Research Institute, India also supported our findings ${ }^{16}$. Still yet our stake holders could not provide country wide cervical cancer screening program due to financial, technical and skilled manpower limitations. The similar scenario was observed also in India where it was estimated that even with a gigantic effort to expand cytology screening services, it will be more impossible to screen one-fourth of total population once in a lifetime in near future ${ }^{17}$.

For this point of views, we have to work hard and financial allotment must be increased in these issues to detect early cervical cancer as it is a quite smart insiduous clinical condition.

But though it is worth mentioning here that a previous study showed the causes of delayed

presentation of the disease where it was evident

that $91 \%$ had lack of information and $37 \%$ had financial issue for not seeking immediate medical attention. Lack of oncologist, referrals and negligence were also other concerning issues in this regard ${ }^{18}$.

In this study, $86.56 \%$ and rest $13.43 \%$ of our patients were suffering from squamous cell carcinoma and adenocarcinoma respectively which were in line of Munoz et al. ${ }^{19}$ We can also assume that the higher parity in our perspective attributed a lot to produce much higher squamous cell carcinoma than adenocarcinoma.

\section{Conclusion:}

Our study reveales that major risk factors are multiparity, early marriage and low socio economic condition. Most of the cervical cancer patients presented in advanced stage and are suffering from squamouas cell carcinoma. The alarming clinical presentation like PV discharge with blood tinge, irregular PV bleeding and postcoital bleeding should be considered seriously for seeking medical attention.

\section{References:}

1. Sharma, V., Kerr, S.H., Kawar, Z., Kerr, D.J. Challenges of cancer control in developing countries; current status and future perspective. Future Oncol. 2011;7 (10),1213-1222.
2. Jacques Ferlay. Cancer Incidence, Mortality and Prevalence Worldwide, IARC. J Clin Oncol 2013; 31(36):4550-4559.

3. Sankaranarayanan R, Buduk AM, Rajkumar R. Effective Screening Programmes for Cervical Cancer in low- and middle-income developing countries. Bull World Health Organ. 2001;79(10):954-962.

4. Akhter PS, uddin MM, Sharia Sk. Patterns of Malignant neoplasm-a three tear study of Bangladesh Medical Journal 1998; 27(2): 29-32.

5. Ashrafunessa, L Shamsuddin, TA Chowdhury, development of Cancer cervix screening programme in Bangladesh

6. Denny L. Cervical Cancer treatment in Africa. Curr Opin Oncol. 2011;23(5):469-474.

7. World Bank, 2017. Bangladesh Poverty and Equity, Retrieved. worldbank. org/poverty/ country/ BGD.

8. Worldometer, 2017. Bangladesh Population, retrieved. world -population / bangladesh-population/.

9. International Agency for Research on Cancer (IARC),Cervical cancer screening IARC Hand book of Cancer prevention Vol. 10.Lyon- France: IARC Press, 2005.

10. World Health Organization ( February 2006, Cancer 2007 Retrievedm, 297.

11. Hospital Cancer Registry Report. National Institute of Cancer Research \& Hospital, 2011-2013. (Short Draft). MOHFW, GOB, NICRH \& WHO.

12. Jabeen $\mathrm{S}$, Islam MJ, Talukder MH, Nurunnabi ASM, Haque M. Pathoepidemiology of Cervical Cancer in National Institute of Cancer Research and Hospital Of Bangladesh. J Dhaka Med Coll. 2014; 23(2) : 203210.

13. Saibua Chichareon, Rolando Herrero, Nubia Mun oz, F. Xavier Bosch, Marcel V. Jacobs, Judith Deacon, Mercedes Santamaria et. al. Risk Factors for Cervical Cancer in Thailand: a Case-Control Study. Journal of the National Cancer Institute, Vol. 90 (1), January 7, 1998:45-8

14. Dipaja PJ, Creasman WT. Invasive Cervical cancer in clinical Gynaecology oncology 4th edition. Mossby year book Boston 1993; 58-125

15. Wagenaar HC, Trimos JB, Postema S et al. Tumor diameter and volume assessed by magnetic resonance imaging in the prediction of outcome for invasive cervical cancer. Gynecol Oncol 2001; 82: 474-482.

16. Gyenwali D, Pariyar J, Onta SR. Factors Associated with Late Diagnosis of Cervical Cancer in Nepal. Asian Pac J Cancer Prev. 2013;14(7):4373-4377.

17 Vinita Trivedi, Rahul Kumar, Rita Rani, Anita Kumari, Richa Chauhan. Cervical cancer awareness in Bihar, India: lots of light but no illumination. IOSR Journal of Dental and Medical Sciences. 2015;14(4):88-92.

18. Stjernsward J, Eddy D, Luthra UK, Stanley K. Plotting a new course for cervical cancer in developing countries. World Health Forum. 1987;8(1):42-45.

19. Munoz N, Franceschi S, Bosetti C, et al. Role of parity and human papillomavirus in cervical cancer: the IARC multicentric case-control study. Lancet. 2002;359(9312):1093-1101. 